\title{
POLAR BEARS AND CLIMATE CHANGE: CERTAINTIES, UNCERTAINTIES, AND HOPE IN A WARMING WORLD
}

\author{
Steven C. Amstrup ${ }^{1,2}$ \\ ${ }^{1}$ Polar Bears International, 810 N. Wallace, Suite E, Bozeman, MT 59715-3020, USA \\ E-mail: samstrup@pbears.org \\ ${ }^{2}$ Department of Zoology and Physiology, University of Wyoming, \\ Laramie, Wyoming 82071, USA
}

\begin{abstract}
The spatiotemporal distribution of arctic sea ice has been in decline for decades. Polar Bears are dependent on the sea ice for access to their marine mammal prey. Observed sea ice declines have been linked to reduced body condition and stature, altered feeding and movement patterns, reduced survival, and population declines in Polar Bears. Based upon projected future sea ice losses, a US Geological Survey (USGS) research team concluded in 2007 that twothirds of the world's Polar Bear population could disappear by mid-century. Yet, adverse effects of changing sea ice have not occurred simultaneously across the Polar Bear's circumpolar range, and projections of future sea ice change differ among regions. Some Polar Bear populations are already in real trouble while those in historically colder regions of the Arctic now may be benefiting from a milder climate. Natural variation in weather and climate means we cannot predict exactly when many critical thresholds will be exceeded. We cannot predict, for example, the first year that reduced access to sea ice will prevent female Polar Bears in a particular region from reaching their traditional denning areas or from achieving weight gains necessary for reproduction. But, we were able to confidently project the distant worldwide future for this iconic species because the fundamental laws of physics guarantee that without mitigating the rise in greenhouse gases we ultimately will exceed these and other critical thresholds. Because their sea ice platform is literally "melting away" the relationship between habitat change and animal welfare may be more clear-cut for Polar Bears than for many other species. Nonetheless, the concept of exceedence thresholds is an important part of understanding the ultimate challenges that anthropogenic climate change brings to all species and ecosystems. Received 14 March 2011, accepted 20 April 2011 .
\end{abstract}

Amstrup, S. C. 2011. Polar Bears and climate change: Certainties, uncertainties, and hope in a warming world. Pages 11-20 in R. T. Watson, T. J. Cade, M. Fuller, G. Hunt, and E. Potapov (Eds.). Gyrfalcons and Ptarmigan in a Changing World, Volume I. The Peregrine Fund, Boise, Idaho, USA. http://dx.doi.org/10.4080/gpcw.2011.0100

Key words: Arctic, climate, general circulation model, greenhouse gases, Polar Bear, sea ice. 
POlar Bears (URSUS MARITIMUS) are highly dependent on arctic sea ice for securing their preferred marine mammal prey. Although Polar Bears will take terrestrial foods when available, abundant data suggest that terrestrial habitats are not likely to provide sustenance adequate to replace marine food sources that will be lost as sea ice availability is reduced (Amstrup 2003, Amstrup et al. 2009). Recent declines in sea ice availability have been associated with reduced body condition, reproduction, survival, and population size for Polar Bears in parts of their range (Stirling et al. 1999, Stirling and Parkinson 2006, Obbard et al. 2006, Regehr et al. 2007, Rode et al. 2010). Observed sea ice declines (Maslanik et al. 1996, Overpeck et al. 2005, Stroeve et al. 2005, Comiso 2006, Serreze et al. 2007), and projected declines (Holland et al. 2006, Zhang and Walsh 2006, Stroeve et al. 2007) suggest that the future welfare of Polar Bears is at risk.

In January 2007, US Secretary of the Interior Dirk Kempthorne, recognized the Polar Bear's dependence on sea ice, and proposed listing the Polar Bear as a threatened species under the Endangered Species Act (ESA, US Fish and Wildlife Service 2007). Classification as a "threatened species" under the ESA requires a determination that the species in question will become "endangered" within the "foreseeable future" throughout all or a significant portion of its range. An "endangered species" is any species that is in danger of extinction throughout all or a significant portion of its range. To inform the Polar Bear listing decision, Secretary Kempthorne requested that the US Geological Survey (USGS) conduct additional analyses of Polar Bears and their sea ice habitats.

\section{Methods OVerview}

In response to Secretary Kempthorne's request, the USGS assembled a team of scientists from within and outside of government to analyze data from a variety of sources. In September 2007 , that team produced nine reports targeting specific questions identified as perti- nent to the final decision by the US Fish and Wildlife Service (USFWS). The USGS studies relied upon general circulation model (GCM) projections of major declines in arctic sea ice extent due to global warming. Projections of how the future of sea ice would affect the future of Polar Bears were derived from outcomes of a Bayesian network (BN) model (Marcot et al. 2006). Projections of the future population status of Polar Bears were made for each of four distinct ecoregional partitions of the worldwide range of Polar Bears (Figure 1). The BN model incorporated projections of sea ice change as well as anticipated likelihoods of changes in several other potential population stressors.

For detailed methods related to Polar Bear projections refer to Amstrup et al. (2008, 2010), Durner et al. (2009) and other reports produced in 2007 (www.usgs.gov/newsroom/ special/polar_bears/). Here, I focus on the fundamental physical foundation for conclusions drawn from those reports, and I point out why that foundation applies to all other species on earth.

\section{Results}

Based upon projected sea ice declines, the USGS reports predicted major future losses in Polar Bear habitats (Durner et al. 2009). Habitat losses, in turn, were linked to declines in body stature and condition (Rode et al. 2010) and important population dynamics features (Regehr et al. 2010, Hunter et al. 2010). Syntheses of these and other recent findings (Amstrup et al. 2008, 2010) suggested that if sea ice habitats decline as most GCMs currently project, Polar Bears could be extirpated by mid-century from the two ecoregions where two-thirds of the world's population currently resides (Figure 1). Those studies also suggested that on-the-ground management activities were unlikely to make a substantive difference in the prognosis for Polar Bears in an increasing greenhouse gas environment. Motivated largely by these findings, Secretary 


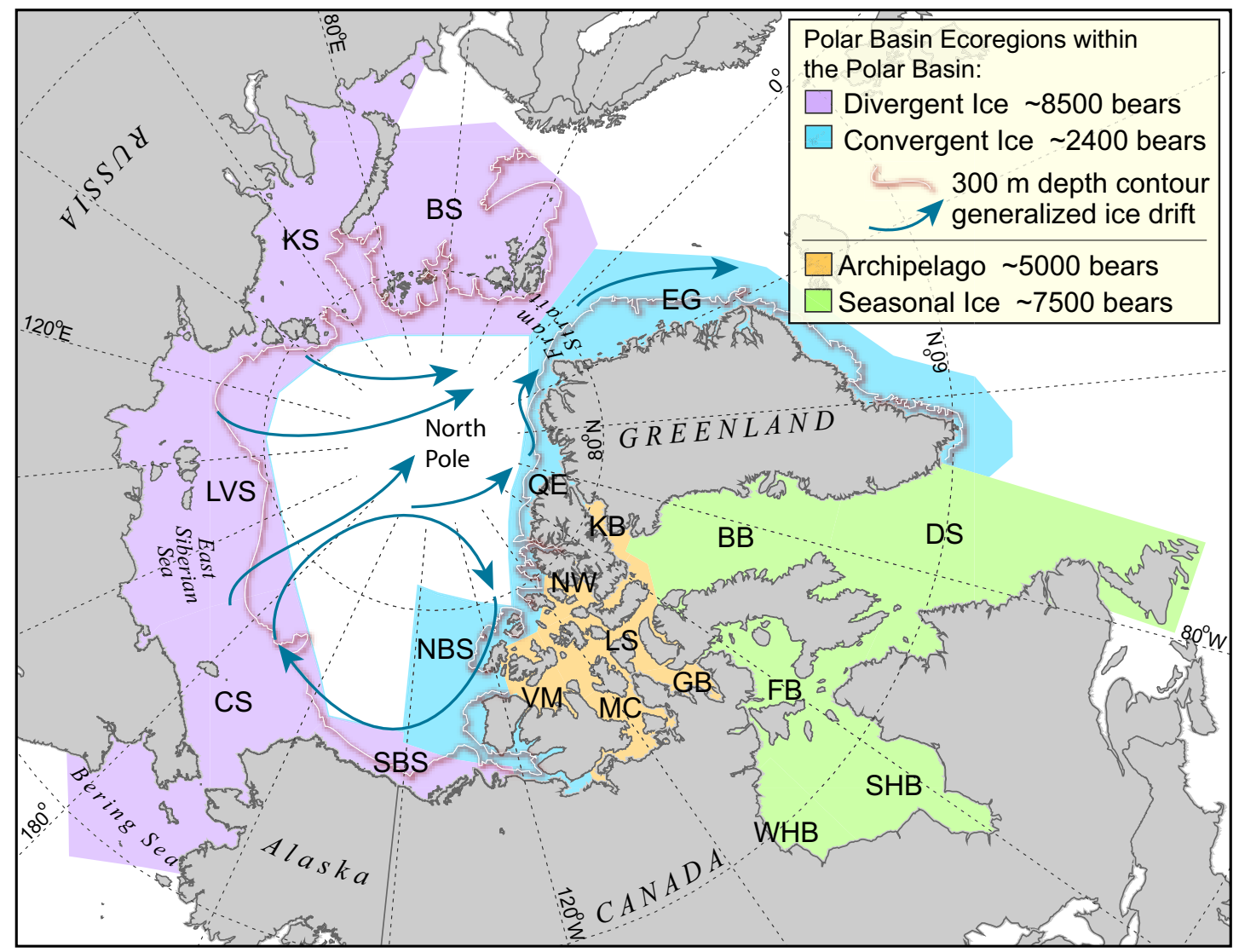

Figure 1. Ecoregions used in analysis of the future global status of Polar Bears. Amstrup et al. (2008, 2010) projected that Polar Bears could be absent from the Divergent Ice and Seasonal Ice ecoregions by mid-century if GHG emissions continue as projected under the business as usual greenhouse gas emissions scenario. Ecoregions include the 19 Polar Bear management units (black initials) as defined by the IUCN Polar Bear Specialists' Group (See Amstrup et al. 2008 for details). Blue lines represent general ice flow patterns.

Kempthorne classified the Polar Bear as a threatened species under the ESA on 15 May 2008 (US Fish and Wildlife Service, 2008).

The projection, in 2007, that two-thirds of the world's Polar Bears could disappear by midcentury was based on the assumption that business as usual greenhouse gas (GHG) emissions would continue into the future (Durner et al. 2009, Regehr et al. 2010, Amstrup et al. 2008). In the same timeframe, the hypothesis that the sea ice cover was about to cross a tipping point and irreversibly collapse also was gaining support (Lindsay and Zhang 2005, Kerr 2007,
Ramanathan and Feng 2008, Lenton et al. 2008, Notz 2009). The 2007 projections did not consider possible benefits of GHG mitigation, but the possible existence of sea ice tipping points suggested future GHG mitigation might not confer a conservation benefit to Polar Bears. Understanding whether mitigation actually could benefit Polar Bears, therefore, was imperative. Using the general circulation model in which sea ice disappearance is most sensitive to warming (Collins et al. 2006, Meehl et al. 2006), Amstrup et al. (2010) demonstrated that substantially more sea ice habitat would be retained if GHG rise is miti- 
gated. Bayesian network model outcomes demonstrated that increased habitat retention under GHG mitigation could allow Polar Bears to persist through the century in greater numbers and more areas than in the business as usual case. The linear relationship we observed between global mean surface air temperature (GMAT) and sea ice habitat illustrated that the key to Polar Bear persistence is controlling temperature rise (Amstrup et al. 2010).

\section{Discussion}

It is increasingly clear that the future welfare of Polar Bears and other wildlife species is dependent upon the degree to which humans will continue to alter the energy balance earth maintains with space. The shortwave radiation coming to earth from the sun ultimately must be balanced by the outgoing long-wave radiation emitted back into space from the earth and its atmosphere (Lutgens and Tarbuck 2004). The earth's atmosphere presently retains just enough energy for just the right amount of time to allow life as we know it to persist. A climate forcing is any factor that perturbs that balance (Hansen and Sato 2004). Increases in solar radiation can provide a positive climate forcing-warming the earth. The shading effects of aerosols released into the atmosphere by volcanoes, for example, can provide a negative climate forcing-cooling the earth by reflecting the sun's energy back into space before it can warm the earth. Increased concentrations of GHGs provide a positive forcing by increasing the degree to which the sun's energy is retained and heats the earth before being reradiated into space.

The important point, related to forecasting the future for Polar Bears and their habitat, is that the application of a persistent climate forcing requires a directional response in the earth's climate. Without a persistent climate forcing, the chaos in the natural system causes the climate (in climate models or in real life) to oscillate - with some periods cooler than average and some warmer. In the natural state, the average or "baseline" around which these oscillations occur is level (Figure 2, green line). With steadily rising GHG forcing, there still will be natural fluctuations in the climate system. Shifting oceanic and atmospheric circulation patterns and other natural forcings (e.g., volcanic eruptions) will continue to cause periods of higher and lower temperatures. These fluctuations, however, will occur over an elevated and rising baseline (Figure 2, orange line). The basic physics of the earth's climate system, therefore, guarantee that the earth's temperature must warm as GHG concentrations rise (Pierrehumbert 2011).

A consequence of unabated GHG-forced global warming is that the likelihood of exceeding particular climate thresholds (e.g., loss of summer sea ice) becomes greater over time. Depending on the natural chaotic behavior of the climate system, and the amplifying effects of positive climate feedbacks, the year in which the increase in global mean temperature exceeds, say $2^{\circ} \mathrm{C}$ might occur before or after the end of the 21 st Century. However, a continuing atmospheric buildup of GHGs makes exceeding this temperature threshold and its ecological ramifications virtually certain. The same premise holds for ice-free conditions in the Arctic. Natural variability and uncertainty in climate feedbacks prevent GCMs from predicting the first year in which the arctic summer will be sea-ice-free. Yet, we know that ice-free arctic summers will become the norm given continued GHG increases.

In this way, climate forecasts are fundamentally different from weather forecasts. Skillful weather forecasting depends critically on accurate representation of the initial state, while the skill of GCM projections depends on the accurate representation of the sensitivity of global climate to GHGs and other climate forcings (Randall et al. 2007). The dependence of GCMs on climate sensitivity versus the dependence of weather forecasts on initial conditions explains the paradox between confidently predicting general aspects of the climate 


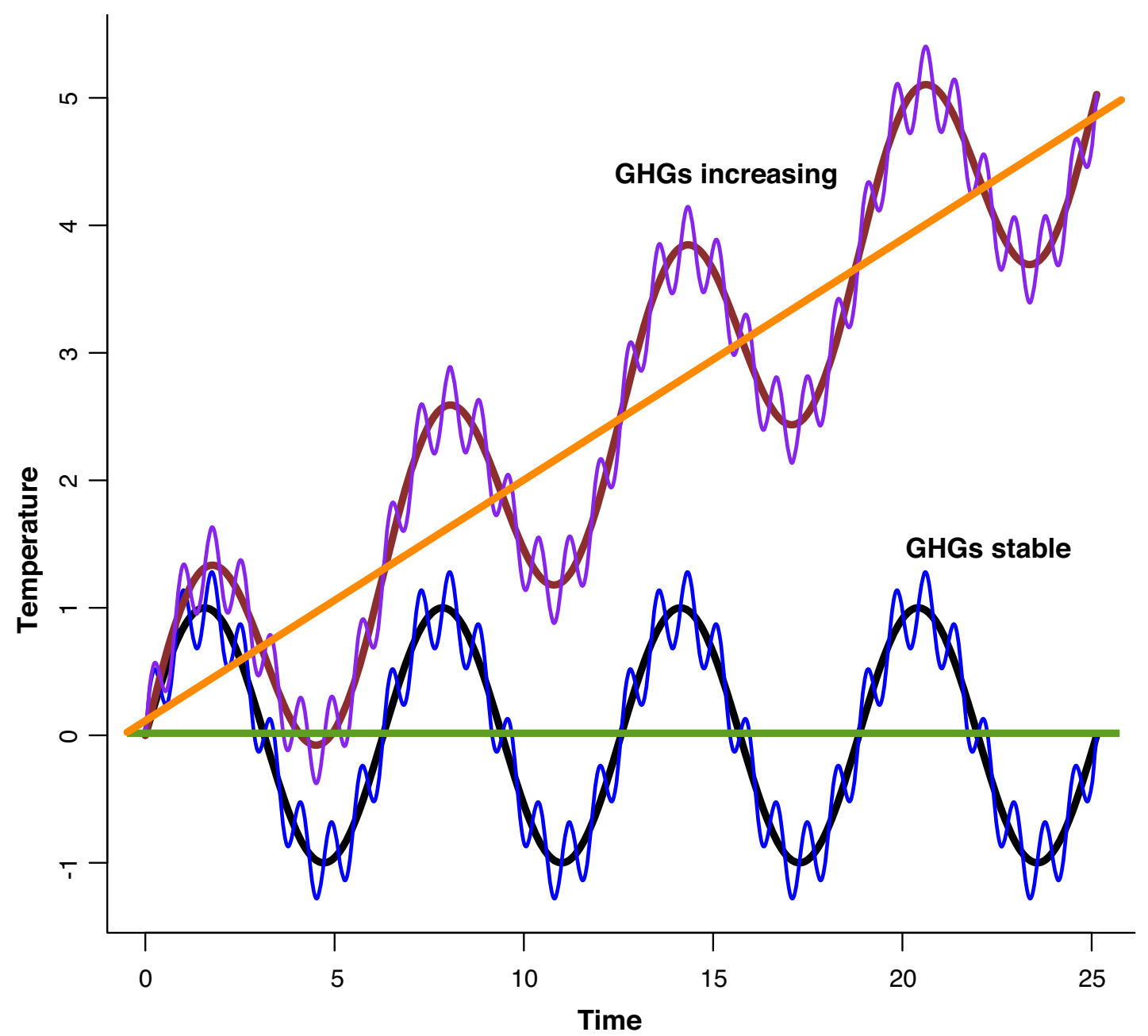

Figure 2. General relationship between temperature and time, with and without persistent greenhouse gas (GHG) forcing. In this conceptual diagram, natural climate fluctuations (black line) like those caused by changes in the state of the Southern Oscillation (El Niño-LaNiña) or the northern annular mode (arctic oscillation) are overlain by storms and other weather fluctuations (blue line) that vary over shorter time-frames and have local or regional rather than global or hemispheric impacts on temperature and other weather variables. In the absence of persistent GHG forcing, weather and climate oscillate around a level baseline (green line). When GHGs continuously rise, natural climate and weather oscillations persist (burgundy and purple lines), but they occur over a rising baseline (orange line).

in 50 years, but not being able to predict next week's weather (Le Treut et al. 2007).

The farther into the future we look, the more likely it is that critical habitat thresholds will have been crossed. We used GCM outputs to project Polar Bear habitat and populations for the middle and latter part of the century, and hence benefited from the certainty of greater sea ice losses for the more distant time frames. We did not focus on the near term. Nor did we attempt to predict the exact year in which particular events might occur. Rather, we relied on projections that temperatures in the middle and 
latter part of the century will be consistent with greatly reduced spatio-temporal availability of sea ice that Polar Bears need to survive.

Because Polar Bears depend on sea-ice, habitat that literally "melts" as temperatures warm, there is an unambiguous relationship between GHGs, temperature, habitat availability, and persistence of the species. Projections of their future, therefore, are more straightforward for Polar Bears than may be possible for other species. Polar Bears depend for their existence on catching seals from the top surface of the sea ice (Amstrup 2003). The seals in turn depend on the epontic ecosystem that develops on the underside of the sea ice. Both predator and prey clearly are in trouble if the ice is unavailable. The sea ice habitat on which both Polar Bears and seals depend can only retreat as temperatures warm. There will be regional differences and uncertainties in ice habitat retreat, but retreat it must.

Gyrfalcons (Falco rusticolus) can live in a fairly broad swath of habitats from north-temperate to arctic conditions, though they breed only in the Arctic (Booms et al. 2008), and they are capable of taking multiple species of prey when available (Potapov and Sale 2005). Predicting the regional impact of warming on Gyrfalcons, therefore, is likely to be much more complicated than it is for Polar Bears. The same can be said of most other species that live in a greater variety of ecosystems and are less specialized foragers than the Polar Bear. But, the principal of threshold exceedance holds for all species. As long as GHG levels in the atmosphere continue to rise, temperatures must rise. At any one time, some species and populations may be benefiting from warming while others decline. Benefits of warming, however, always will be transitory. For example, presently Polar Bears near the southern extreme of their range are declining as a result of climate warming induced habitat loss (Stirling et al. 1999, Regehr et al. 2007). In contrast, Polar Bears near the current northern extreme of their range have historically been limited by extreme cold and heavy sea ice. Some of these subpopulations may now be benefiting from a milder climate, though we have no data to verify this. As warming continues, however, these northern bears will transition from a situation where they may be benefiting from climate change to one in which they are suffering from it, as are their southern cousins now. As long as GHG concentrations continue to rise, there will be no ecosystems that are persistent in the long run, and no way to manage for sustainability.

\section{Conclusion}

Despite the distraction caused by recent heavy snows in some regions and unusual cold in others, temperatures around the world are rising (Figure 3). They will continue to rise as long as atmospheric concentrations of GHGs rise. The longer we allow GHG concentrations to rise, the more undesirable ecological thresholds will be exceeded, and the greater will be the costs borne by future generations that must handle the climate changes we now are creating.

Without GHG mitigation, we simply will become Polar Bear historians. However, this dire prediction is based upon continued business as usual emissions and is not unavoidable. We have shown that mitigation of GHG rise provides the opportunity to preserve sustainable Polar Bear populations (Amstrup et al. 2010). The benefits of mitigation efforts that will preserve sustainable Polar Bear populations extend to other species including Gyrfalcons and humans. It is up to us to make sure that we take advantage of that opportunity in a timely manner (Derocher 2010).

\section{ACKNOWLEDGMENTS}

The research findings discussed here were made possible by support from the US Geological Survey, and the assistance of George Durner, Geoff York, and Kristin Simac who worked there with me. Bruce Marcot's thinking and analytical help guided me in under- 
Barrow, Alaska

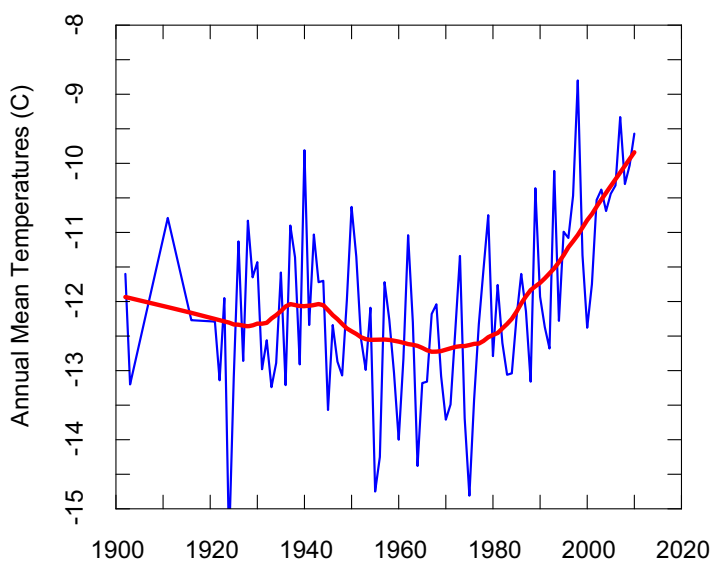

Phoenix, Arizona

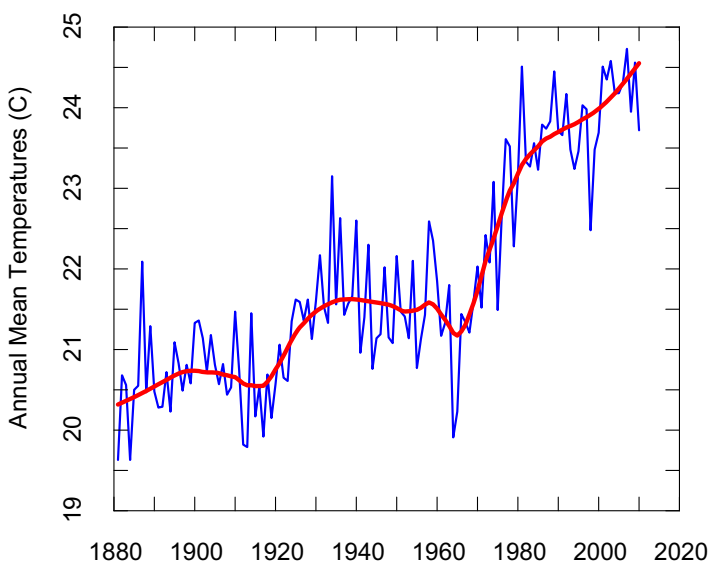

Washington, DC

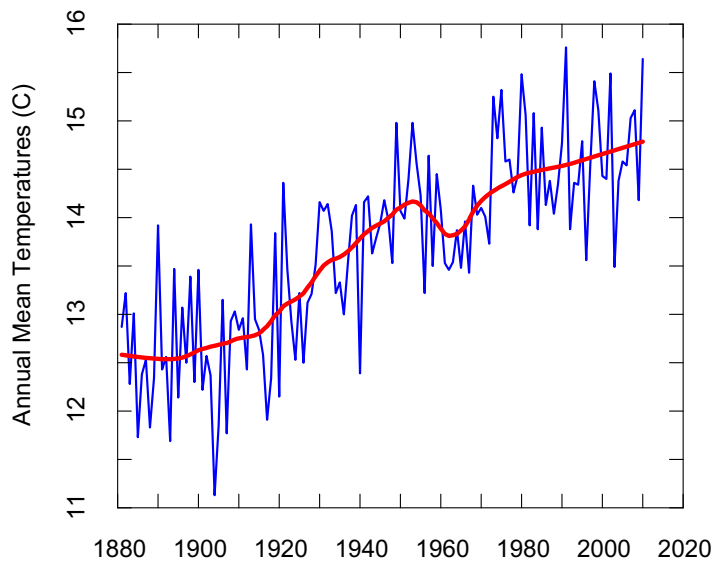

Figure 3. Examples of recent warming observed in four diverse North American locales. There are ups and downs, and the pattern and rate of warming has varied among regions. Nearly all areas, however, have warmed considerably in recent decades. Shown here are annual mean temperatures (blue) and running average (red) of those annual temperatures calculated by the super smoother function in the $\mathrm{R}$ programming language. Plots were derived from worldwide climatology data maintained by the Goddard Institute for Space Studies (http://data.giss.nasa.gov/gistemp/).

standing the synthesis of a diverse pool of information into an understandable projection of the probable future. Dave Douglas's ability to extract, summarize, and analyze remote sensing data was essential in development of my understanding of sea ice present and future.
I thank Cecilia Bitz for thoughts and discussions about climate and sea ice projections. I am especially grateful for long discussions about weather and climate with Eric DeWeaver and for his many suggestions. Finally, I am 
grateful to Polar Bears International for time to think about the big picture.

\section{Literature Cited}

Amstrup, S. C. 2003. Polar bear. In G. A. Feldhammer, B. C. Thompson, J. A. Chapman (Eds.). Wild Mammals of North America: Biology, Management, and Conservation, second edition. Johns Hopkins University Press, Baltimore, Maryland, USA.

Amstrup, S. C., H. Caswell, E. DeWeaver, I. Stirling, D. C. Douglas, B. G. Marcot, AND C. M. Hunter. 2009. Rebuttal of "Polar bear population forecasts: a publicpolicy audit." Interfaces 39(4):353-369.

Amstrup, S. C., E. DeWeaver, D. C. DouGlas, B. C. Marcot, G. M. Durner, C. M. BITZ, AND D. A. B AILEY. 2010. Greenhouse gas mitigation can reduce sea-ice loss and increase polar bear persistence. Nature 468:955-958.

Amstrup, S. C., B. G. Marcot, and D. C. Douglas. 2008. A Bayesian network modeling approach to forecasting the 21 st century world-wide status of polar bears. Pages 213-268 in E. T. DeWeaver, C. M. Bitz, and L.-B. Tremblay (Eds.). Arctic Sea Ice Decline: Observations, Projections, Mechanisms, and Implications. Geophysical Monograph Series, Vol. 180, American Geophysical Union, Washington, DC, USA.

Booms, T. L., T. J. CADE, AND N. J. Clum. 2008. Gyrfalcon Falco rusticolus. In A. Poole (Ed.). The Birds of North America Online. Cornell Lab of Ornithology, Ithaca, New York, USA. http://dx.doi.org/10.2173/bna.114

Collins, W. D., C. M. BITZ, M. L. BlackMON, G. B. Bonan, C. S. Bretherton, J. A. Carton, P. Chang, S. C. Doney, J. J. HACK, T. B. HENDERSON, J. T. KIEHL, W. G. Large, D. S. McKenna, B. D. Santer, AND R. D. SMITH. 2006. The Community Climate System Model Version 3 (CCSM3). Journal of Climate 19:21222143.
Comiso, J. C. 2006. Abrupt decline in the Arctic winter sea ice cover. Geophysical Research Letters 33, L18504, http://dx.doi.org/10.1029/2006GL027341.

DEROCHER, A. E. 2010. The prospects for polar bears. Nature 468:905-906.

Durner, G. M., D. C. Douglas, R. M. NeILson, S. C. Amstrup, T. L. MCDonald, I. Stirling, M. Mauritzen, E. W. Born, O. WiIg, E. DeWeaver, M. C. Serreze, S. E. Belikov, M. M. Holland, J. Maslanik, J. Aars, D. A. B AILEY, AND A. E. Derocher. 2009. Predicting 21st century polar bear habitat distribution from global climate models. Ecological Monographs 79:25-58.

Hansen, J., AND M. Sato. 2004. Greenhouse gas growth rates. Proceedings of the National Academy of Sciences 101(46): 16109-16114. http://dx.doi.org/10.1073/0406982101

Holland, M. M., C. M. Bitz, AND B. TRemBLAY. 2006. Future abrupt reductions in the summer Arctic sea ice. Geophysical Research Letters, 33, L23503. http://dx.doi.org/10.1029/2006GL028024.

Hunter, C. M., H. Caswell, M. C. Runge, E. V. REgeHr, S. C. AMSTRUP, AND I. STIRLING. 2010. Climate change threatens polar bear populations: A stochastic demographic analysis. Ecology 91:2883-2897.

KerR, R. A. 2007. Is battered Arctic sea ice down for the count? Science 318:33-34.

Lenton, T. M., H. Held, E. Kriegler, J W. Hall, W. LuCht, S. RahmSTORF, AND H. J. SCHELlNHUBER. 2008. Tipping elements in the Earth's climate system. Proceedings of the National Academy Sciences 105:17861793.

Le Treut, H., R. Somerville, U. Cubasch, Y. Ding, C. Mauritzen, A. Mokssit, T. Peterson, AND M. Prather. 2007. Historical overview of climate change. In $\mathrm{S}$. Solomon, D. Qin, M. Manning, Z. Chen, M. Marquis, K. B. Averyt, M. Tignor, and H. L. Miller (Eds.). Climate Change 2007: The Physical Science Basis. Cambridge University Press, Cambridge, New York, USA. 
LiNDSAY, R. W., AND J. ZHANG. 2005. The thinning of Arctic sea ice, 1988-2003: Have we passed a tipping point? Journal of Climate. 18(22):4879-4894.

Lutgens, F. K., E. J. TARbuck. 2004. The Atmosphere. Pearson Prentice Hall, Upper Saddle River, New Jersey, USA.

Marcot, B. G., J. D. Steventon, G. D. Sutherland, AND R. K. MCCANn. 2006. Guidelines for developing and updating Bayesian belief networks applied to ecological modeling and conservation. Canadian Journal of Forest Research 36:3063-3074.

Maslanik, J. A., M. C. Serreze, and R. G. BARRY. 1996. Recent decreases in Arctic summer ice cover and linkages to atmospheric circulation anomalies. Geophysical Research Letters 23(13):1677-1680.

Meehl, G. A., W. M. Washington, B. D. Santer, W. D. Collins, J. M. Arblaster, A. Hu, D. M. Lawrence, H. Teng, L. E. Buja, AND W. G. Strand, JR. 2006. Climate change projections for the 21 st century and climate change commitment in the CCSM3. Journal of Climate 19:25972616.

Notz, D. The future of ice sheets and sea ice: Between reversible retreat and unstoppable loss. 2009. Proceedings of the National Academy of Sciences 106:20590-20595.

Obbard, M. E., M. R. L. Cattet, T. Moody, L. R. Walton, D. Potter, J. Inglis, AND C. CHENIER. 2006. Temporal trends in the body condition of southern Hudson Bay polar bears. Climate Change Research Information Note, No. 3. Applied Research and Development Branch, Ontario Ministry of Natural Resources, Sault Sainte Marie, Ontario, Canada.

Overpeck, J. T., M. Sturm, J. A. Francis, D. K. Perovich, M. C. Serreze, R. Benner, AND E. C. CARMACK. 2005. Arctic system on trajectory to new, seasonally ice-free state. Eos Transactions of the American Geophysical Union 86(34):309, 312-313.
PierReHUMBert, R. T. 2011. Infrared radiation and planetary temperature. Physics Today 64(1):33-38.

Potapov, E., And R. Sale. 2005. The Gyrfalcon. T. \& A. D. Poyser, London, UK.

Ramanathan, V., and Feng, Y. 2008. On avoiding dangerous anthropogenic interference with the climate system: Formidable challenges ahead. Proceedings of the National Academy of Sciences 105:1424514250.

Randall, D. A., R. A. Wood, S. Bony, R. Colman, T. Fichefet, J. Fyfe, and V. KatTsOv. 2007. Climate models and their evaluation. In S. Solomon, D. Qin, M. Manning, Z. Chen, M. Marquis, K. B. Averyt, M. Tignor, and H. L. Miller (Eds.). Climate Change 2007: The Physical Science Basis. Cambridge University Press, Cambridge, New York, USA.

REgeHr, E. V., N. J. LunN, S. C. AMSTRUP, AND I. STIRLING. 2007. Effects of earlier sea ice breakup on survival and population size of polar bears in western Hudson Bay. Journal of Wildlife Management 71:2673-2683.

Regehr, E. V., C. M. Hunter, H. Caswell, S. C. Amstrup, And I. StiRling. 2010. Survival and breeding of polar bears in the southern Beaufort Sea in relation to sea ice. Journal of Animal Ecology 79:117-127.

Rode, K. D., S. C. Amstrup, And E. V. REGEHR. 2010. Reduced body size and cub recruitment in polar bears associated with sea ice decline. Ecological Applications 20:768-782.

Serreze, M. C., M. M. Holland, and J. Stroeve. 2007. Perspectives on the Arctic's shrinking sea-ice cover. Science 315(5818):1533-1536.

STIRLING, I., N. J. LUNN, AND J. IACOZZA. 1999. Long-term trends in the population ecology of polar bears in western Hudson Bay in relation to climatic change. Arctic 52:294306.

Stirling, I., AND C. L. PARKinson. 2006. Possible effects of climate warming on selected populations of polar bears (Ursus 
maritimus) in the Canadian Arctic. Arctic 59(3):261-275.

Stroeve J., M. M. Holland, W. Meier, T. Scambos, AND M. Serreze. 2007. Arctic sea ice decline: Faster than forecast. Geophysical Research Letters 34, L09501. http://dx.doi.org/10.1029/2007GL029703.

Stroeve, J. C., M. C. Serreze, F. Fetterer, T. Arbetter, W. Meier, J. Maslanik, AND K. KNOWLES. 2005. Tracking the Arctic's shrinking ice cover: Another extreme September minimum. Geophysical Research Letters 32, L04501.

http://dx.doi.org/10.1029/2007GL029703.

US FISH AND WILDLIFE SERVICE. 2007. Endangered and threatened wildlife and plants; 12-month petition finding and proposed rule to list the polar bear (Ursus maritimus) as threatened throughout its range. Federal Register 72(5):1064-1099.

US FISH AND WildLIFE SERVICE. 2008. Endangered and threatened wildlife and plants: Determination of threatened status for the polar bear (Ursus maritimus) throughout its range. Federal Register 73(95):2821228303.

ZhANG, X. D., AND J. E. WALSH. 2006. Toward a seasonally ice-covered Arctic Ocean: Scenarios from the IPCC AR4 model simulations. Journal of Climate 19(9):17301747. 